\title{
Physical fitness of medical residents: Is the health of surgical residents at risk?
}

\author{
David L. Perrin, MD \\ Dean M. Cordingley, MSc \\ Jeff R. Leiter, PhD \\ Peter B. MacDonald, MD
}

The preliminary data from this study were presented at the Canadian Society for Exercise Physiology annual general meeting, Hamilton, Ont., Oct. 14-17, 2015.

Accepted Jan. 22, 2018; Early-released Aug. 1, 2018

\section{Correspondence to: \\ J. Leiter \\ Pan Am Clinic \\ 75 Poseidon Bay \\ Winnipeg MB R3M 3E4 \\ Jleiter@panamclinic.com}

DOI: $10.1503 /$ cjs. 012617
Background: Postgraduate medical residency programs are laborious and timeintensive, and can be physically, intellectually and emotionally demanding. These working conditions may lead to the neglect of personal health and well-being. The objective of this study was to compare the anthropometric and fitness characteristics of surgical and nonsurgical medical residents. We hypothesized that there is a difference in physical health between these 2 groups.

Methods: Medical residents completed a demographic information questionnaire and were assessed by trained staff for height, weight, body fat percentage, muscular strength and endurance, and peak oxygen consumption $\left(\dot{\mathrm{V}}_{\mathrm{O}_{\text {peak }}}\right)$. The average number of working hours per week was also documented.

Results: Forty-five residents (21 surgical and 24 nonsurgical; 31 men and 14 women) participated in the study. Surgical residents worked more hours per week on average than nonsurgical residents $(p=0.02)$ and had a higher body mass index $(\mathrm{BMI})(p=$ $0.04)$ and lower $\dot{V}_{\mathbf{O}_{2 \text { peak }}}(p=0.01)$.

Conclusions: Surgical residents worked more hours than nonsurgical residents, which may have contributed to their higher BMI and lower aerobic fitness levels. Despite a heavy workload, it is important for all medical residents to find strategies to promote a healthy lifestyle for both themselves and their patients to ensure long-term well-being.

Contexte : En médecine, les programmes de résidence postdoctoraux sont fastidieux et chronovores; et ils peuvent être exigeants physiquement, intellectuellement et émotivement. De telles conditions de travail forcent parfois les résidents à négliger leur santé et leur bien-être personnels. L'objectif de cette étude était de comparer les caractéristiques anthropométriques et la forme physique des résidents de chirurgie et d'autres spécialités médicales. Selon notre hypothèse, ces 2 groupes ne présentent pas le même état de santé physique.

Méthodes : Les résidents ont répondu à un questionnaire démographique et des assistants dument formés ont mesuré leur taille, leur poids, leur pourcentage de graisse corporelle, leur force musculaire, leur endurance et leur consommation d'oxygène maximale $\left(\dot{\mathrm{V}}_{\mathbf{2}_{\max }}\right)$. Le nombre d'heures de travail hebdomadaires a aussi été pris en compte.

Résultats : Quarante-cinq résidents (21 de chirurgie et 24 d'autres spécialités; 31 hommes et 14 femmes) ont participé à l'étude. Les résidents en chirurgie travaillaient en moyenne plus d'heures par semaine que les autres résidents $(p=0,02)$ et présentaient un indice de masse corporelle (IMC) plus élevé $(p=0,04)$ et une $\dot{V}_{2_{\max }}$ plus basse $(p=0,01)$.

Conclusion : Les résidents en chirurgie travaillaient plus d'heures que les autres résidents, ce qui peut avoir contribué à leur IMC plus élevé et à leur moins bonne capacité aérobique. Malgré la lourdeur de leur fardeau de travail, il est important que tous les résidents en médecine trouvent des stratégies pour adopter de saines habitudes de vie pour eux-mêmes et leurs patients, et assurer leur mieux-être à long terme. 
ostgraduate medical residency is an extremely laborious and time-intensive process. Medical residents often disregard their health in order to benefit their patients and to improve their medical training, ${ }^{1,2}$ which may be detrimental to their mental, physical and social health. ${ }^{3}$ Long working hours in the medical field have been associated with burnout, ${ }^{4}$ sleep deprivation ${ }^{5}$ and decreased quality of life. ${ }^{6,7}$ For residents, these working conditions can increase the risk of health issues such as obesity, diabetes and cardiovascular disease. ${ }^{8}$ These issues not only affect the health status of residents but also decrease the quality of interactions with patients and family, ${ }^{9}$ and increases the rate of medical errors. ${ }^{9,10}$

Despite the affluence of research investigating the benefits of physical fitness, few investigators have explored the effect of residency on the physical health of trainees. The few studies published on the fitness of medical residents are discouraging. Suskin and colleagues ${ }^{11}$ found that a group of 20 residents experienced decreased aerobic fitness throughout rotations, and Arora and colleagues ${ }^{12}$ reported similar results in military physicians. In a recent survey, internal medicine residents reported a significant decrease in physical activity once they began residency and noted time constraints as the primary barrier. ${ }^{2}$

Although there is an association between residency and decreased fitness, to our knowledge, there are no studies comparing the health status of residents from various specialties. The purpose of this study was therefore to compare the working hours and physical fitness levels of surgical and nonsurgical residents. We hypothesized that there is a difference in physical health between these 2 groups.

\section{Methods}

\section{Sample size and sampling methods}

Ethics approval for the study was received from the University of Manitoba institutional review board, and all participants consented. We calculated sample size from previous research, ${ }^{13}$ which indicated that a minimum of 10 participants were required per group to show a difference in the maximal volume of oxygen consumption $\left(\dot{\mathrm{V}}_{\mathrm{O}_{\text {2peak }}}\right)$ with $\alpha=0.05$ and $\beta=0.80$. A recruitment email describing the nature of the study was sent to all residents at the University of Manitoba by means of a general distributing list.

\section{Study protocol}

Data collection occurred from May to August 2013. After completing a demographic information questionnaire, each resident participated in a fitness-assessment protocol including anthropometric, strength, endurance and aerobic fitness variables. Testing was conducted by a personal trainer certified by the Canadian Society for Exercise
Physiology (with additional graduate-level training in fitness testing and assessment) who followed strict protocols. Heart rate and blood pressure were assessed with a blood pressure monitor (Life Source) after 5 minutes of rest. Body mass and height were measured (Seca) to the nearest $0.1 \mathrm{~kg}$ and $0.5 \mathrm{~cm}$, respectively, with the resident wearing shorts, shirt and socks. Body mass index (BMI) was calculated, and body fat percentage was determined by means of 6 skinfold measurements (baseline skinfold caliper, Chattanooga Group). ${ }^{14}$ Grip strength was also measured (Jamar hand dynamometer, Sammons Preston Rolyan). ${ }^{15}$

Abdominal and core endurance were assessed by means of a maximum sit-up test. The participant was instructed to lie supine on a pad with knees bent to $90^{\circ}$ and perform as many sit-ups as possible, keeping hands by ears, touching elbows to knees and keeping contact between heels and the pad. The maximal number of sit-ups was determined as the point at which the resident could no longer touch elbows to knees or could not maintain form during the repetition.

Aerobic fitness was assessed by measuring $\dot{V}_{\mathbf{O}_{2 \text { peak }}}$ throughout a graded exercise test with an Oxycon mobile metabolic measurement system (CareFusion Corporation) that was calibrated before each test. Heart rate was recorded every 20 seconds (FT1, Polar Electro). The graded exercise test protocol was modified from a previously established protocol ${ }^{16}$ to include a starting workload of $70 \mathrm{~W}$. Procedures were explained thoroughly to each participant, and all questions were answered before testing. The test was terminated if the resident could no longer pedal or was unable to pedal at a rate to maintain the required power output. Maximal volume of oxygen consumption was determined as the point at which the participant reached volitional exhaustion along with at least 1 of the following: a peak and plateau in oxygen uptake, heart rate close to maximum predicted for age or respiratory exchange ratio greater than $1.1 .{ }^{17}$

\section{Statistical analysis}

All data are presented as mean and standard deviation (SD) unless noted otherwise. We performed separate one-way analyses of variance to determine mean differences for all variables between the sexes, residency program and sex between each program. If significance was indicated, we performed the Tukey honest significant difference test. We carried out all statistical analyses using SPSS 20.0 (IBM Corp.) with a significance level of $\alpha=0.05$.

\section{Results}

Forty-five residents volunteered for the study: 21 surgical residents (15 men [mean age 29.9 (SD 3.3) yr, mean height 179.4 (SD 5.6) cm, mean weight 87.8 (SD 13.6) $\mathrm{kg}$ ] and 6 women [mean age 30.5 (SD 2.1) yr, mean height 170.8 (SD 
6.4) $\mathrm{cm}$, mean weight 63.6 (SD 5.9) kg] and 24 nonsurgical residents (16 men [mean age 29.3 (SD 3.7) yr, mean height 181.2 (SD 7.1) cm, mean weight 80.4 (SD 11.1) kg] and 8 women [mean age 30.0 (SD 2.0) yr, mean height 170.2 (SD 8.9) $\mathrm{cm}$, mean weight 63.1 (SD 13.1) kg]).

The data for 1 male nonsurgical resident were removed from the working time analysis because of recent vacation, and the data for 1 female nonsurgical resident were removed from the aerobic fitness analysis because she failed to achieve a maximal test.

There was no difference between the surgical and nonsurgical residents in year of residency $(p=0.2)$, mean age $(p=0.6)$ or reported number of hours of exercise per week $(p=0.7)$ (Table 1). Surgical residents worked more hours per week on average than nonsurgical residents $(p=0.02)$. There was no difference between the 2 groups in height $(p=0.8)$, weight $(p=0.2)$ or body fat percentage $(p=0.3)$. Surgical residents had a greater BMI than nonsurgical residents $(p=0.04)$. At rest, heart rate $(p=0.4)$, systolic blood pressure $(p=0.3)$ and diastolic blood pressure $(p=0.4)$ did not differ between the 2 groups. During aerobic testing, there was no difference in maximal heart rate $(p=0.3)$ or peak power output achieved $(p=0.3)$, but surgical residents exhibited a lower mean $\dot{V}_{\mathbf{O}_{2 \text { peak }}}$ than nonsurgical residents $(p=0.01)$. There was no difference between the groups in grip strength $(p=0.9)$ or endurance (sit-ups, $p=0.2$ ).

The results by sex and by sex and residency program are shown in Table 2 and Table 3, respectively.

\section{Discussion}

We found that surgical residents had a greater BMI, a higher body fat percentage and lower aerobic fitness than nonsurgical residents. Although there was no difference in age or year of residency, surgical residents were required to work more hours each week than nonsurgical residents. The grueling hours of a surgical residency are well known, as these residents are required to learn and develop highly intricate skill sets. According to the American College of Sports Medicine, ${ }^{18}$ compared to age-matched normative data, male surgical residents were in the 20th percentile, whereas male nonsurgical residents were in the 70th percentile. The lower health-related scores among male surgical residents in the current study may have been due to the increased hours worked per week, which would limit the time and energy they had to devote to their health.

Disregarding stream of residency, there were many differences that would be expected between our male and female participants. Male participants were taller and heavier and had a higher BMI and lower body fat percentage than female participants. These differences are consistent with the general population. ${ }^{19,20}$ Male participants had a higher resting systolic blood pressure than female participants, which is consistent with a review by Reckelhoff. ${ }^{21}$ Male participants had greater grip strength, higher $\dot{\mathrm{V}}_{\mathrm{O}_{\text {peak }}}$ and higher maximal heart rate, and achieved a greater power output during the final stage of the graded exercise test. The greater grip strength, ${ }^{22}$ power output ${ }^{23}$ and $\dot{\mathrm{V}}_{\mathrm{O}_{\text {peak }}}{ }^{18}$ results are consistent with previous research.

Among the women, there were no differences between the surgical and nonsurgical residents, likely because of the

Table 1. Comparison of surgical and nonsurgical residents

\begin{tabular}{|c|c|c|}
\hline \multirow[b]{2}{*}{ Characteristic } & \multicolumn{2}{|c|}{ Group; mean $\pm S D^{*}$} \\
\hline & $\begin{array}{c}\text { Surgical } \\
n=21\end{array}$ & $\begin{array}{c}\text { Nonsurgical } \\
n=24\end{array}$ \\
\hline Year of residency, median (IQR) & $2.0(2.0)$ & $3.0(3.0)$ \\
\hline Age, yr & $30.0 \pm 3.0$ & $29.5 \pm 3.2$ \\
\hline Time worked per week, h & $70.5 \pm 15.9$ & $58.9 \pm 16.0 \dagger$ \\
\hline Time spent exercising per week, $\mathrm{h}$ & $4.2 \pm 2.6$ & $3.9 \pm 2.5$ \\
\hline Resting heart rate, beats/min & $70.0 \pm 9.0$ & $67.4 \pm 12.8$ \\
\hline Systolic blood pressure, mm Hg & $125.1 \pm 12.8$ & $120.8 \pm 15.6$ \\
\hline Diastolic blood pressure, $\mathrm{mm} \mathrm{Hg}$ & $77.4 \pm 9.3$ & $75.4 \pm 8.3$ \\
\hline Height, cm & $177.0 \pm 7.0$ & $177.5 \pm 9.2$ \\
\hline Weight, kg & $80.9 \pm 16.3$ & $74.7 \pm 14.2$ \\
\hline Body mass index & $25.7 \pm 4.1$ & $23.5 \pm 2.9 \dagger$ \\
\hline Grip strength, kg & $106.7 \pm 23.3$ & $105.9 \pm 29.8$ \\
\hline Sit-ups, no. of repetitions & $18.1 \pm 10.8$ & $30.8 \pm 39.0$ \\
\hline$\%$ body fat & $18.3 \pm 5.6$ & $16.4 \pm 6.0$ \\
\hline$\dot{\mathrm{V}}_{2 \text { peak }} \mathrm{mL} /(\mathrm{kg} \cdot \mathrm{min})$ & $34.2 \pm 6.1$ & $39.8 \pm 8.1 \dagger$ \\
\hline Maximum heart rate, beats/min & $180.6 \pm 10.8$ & $184.2 \pm 12.4$ \\
\hline Power output, W & $297.1 \pm 62.2$ & $317.8 \pm 65.8$ \\
\hline $\begin{array}{l}\text { IQR = interquartile range; } \mathrm{SD}=\text { standard } \\
\text { consumption. } \\
{ }^{*} \text { Except where noted otherwise. } \\
\dagger p<0.05 .\end{array}$ & ion; $\dot{V O}_{2 \text { peak }}=\max$ & olume of oxygen \\
\hline
\end{tabular}

Table 2. Comparison of male and female residents

\begin{tabular}{|c|c|c|}
\hline \multirow[b]{2}{*}{ Characteristic } & \multicolumn{2}{|c|}{ Sex; mean $\pm S D^{*}$} \\
\hline & $\begin{array}{l}\text { Male } \\
n=31\end{array}$ & $\begin{array}{c}\text { Female } \\
n=14\end{array}$ \\
\hline Year of residency, median (IQR) & $2.0(2.0)$ & $3.0(1.5)$ \\
\hline Age, yr & $29.5 \pm 3.5$ & $30.2 \pm 2.0$ \\
\hline Time worked per week, h & $63.9 \pm 14.5$ & $65.6 \pm 21.5$ \\
\hline Time spent exercising per week, $\mathrm{h}$ & $4.4 \pm 2.8$ & $3.4 \pm 1.7$ \\
\hline Resting heart rate, beats/min & $68.1 \pm 10.9$ & $69.7 \pm 12.0$ \\
\hline Systolic blood pressure, $\mathrm{mm} \mathrm{Hg}$ & $128.5 \pm 11.7$ & $110.2 \pm 11.7 \dagger$ \\
\hline Diastolic blood pressure, $\mathrm{mm} \mathrm{Hg}$ & $76.3 \pm 8.9$ & $76.5 \pm 10.0$ \\
\hline Height, cm & $180.4 \pm 6.4$ & $170.4 \pm 7.6 \dagger$ \\
\hline Weight, kg & $84.0 \pm 12.7$ & $63.3 \pm 10.3+$ \\
\hline Body mass index & $25.8 \pm 3.4$ & $21.7 \pm 2.4 \dagger$ \\
\hline Grip strength, kg & $121.4 \pm 15.4$ & $72.9 \pm 10.6+$ \\
\hline Sit-ups, no. of repetitions & $22.3 \pm 13.8$ & $30.6 \pm 50.2$ \\
\hline$\%$ body fat & $14.6 \pm 4.0$ & $23.1 \pm 5.0 \dagger$ \\
\hline$\dot{\mathrm{V}}_{2 \text { peak }}, \mathrm{mL} /(\mathrm{kg} \cdot \mathrm{min})$ & $38.8 \pm 8.1$ & $33.2 \pm 4.8 \dagger$ \\
\hline Maximum heart rate, beats/min & $185.7 \pm 10.3$ & $174.9 \pm 11.5 \dagger$ \\
\hline Power output, W & $331.0 \pm 59.7$ & $253.1 \pm 64.3 \dagger$ \\
\hline $\begin{array}{l}\text { IQR = interquartile range; } S D=\text { standard } \\
\text { consumption. } \\
\text { *Except where noted otherwise. } \\
t p<0.05 .\end{array}$ & $; \dot{V}_{2 \text { zeak }}=$ maxima & ume of oxygen \\
\hline
\end{tabular}


Table 3. Comparison of residents by sex and residency program

\begin{tabular}{|c|c|c|c|c|}
\hline \multirow[b]{2}{*}{ Characteristic } & \multicolumn{2}{|c|}{ Male; mean \pm SD* } & \multicolumn{2}{|c|}{ Female; mean $\pm S D^{*}$} \\
\hline & $\begin{array}{c}\text { Surgical } \\
n=15\end{array}$ & $\begin{array}{c}\text { Nonsurgical } \\
n=16\end{array}$ & $\begin{array}{c}\text { Surgical } \\
n=6\end{array}$ & $\begin{array}{c}\text { Nonsurgical } \\
n=8\end{array}$ \\
\hline Year of residency, median (IQR) & $1.0(2.0)$ & $2.5(3.0)$ & $3.0(1.5)$ & $3.0(2.5)$ \\
\hline Time worked per week, h & $63.7 \pm 14.2$ & $59.1 \pm 13.6$ & $75.0 \pm 20.2$ & $58.5 \pm 20.8$ \\
\hline Time spent exercising per week, $\mathrm{h}$ & $4.5 \pm 2.7$ & $4.3 \pm 2.9$ & $3.6 \pm 2.2$ & $3.2 \pm 1.5$ \\
\hline Resting heart rate, beats/min & $69.5 \pm 9.1$ & $66.7 \pm 12.5$ & $71.0 \pm 9.6$ & $68.8 \pm 14.2$ \\
\hline Systolic blood pressure, $\mathrm{mm} \mathrm{Hg}$ & $130.1 \pm 9.1$ & $127.0 \pm 13.7$ & $112.7 \pm 12.6$ & $108.4 \pm 11.4$ \\
\hline Diastolic blood pressure, $\mathrm{mm} \mathrm{Hg}$ & $78.3 \pm 9.2$ & $74.4 \pm 7.1$ & $75.2 \pm 9.9$ & $77.5 \pm 10.6$ \\
\hline Body mass index & $27.26 \pm 3.8$ & $24.4 \pm 2.4 \dagger$ & $21.8 \pm 1.5$ & $21.7 \pm 3.1$ \\
\hline Grip strength, kg & $118.7 \pm 13.3$ & $123.9 \pm 17.3$ & $76.7 \pm 12.7$ & $70.0 \pm 8.5$ \\
\hline Sit-ups, no. of repetitions & $20.5 \pm 10.7$ & $24.1 \pm 16.4$ & $12.3 \pm 9.6$ & $44.3 \pm 64.1$ \\
\hline$\%$ body fat & $16.1 \pm 4.6$ & $13.2 \pm 2.6 \dagger$ & $23.6 \pm 4.2$ & $22.8 \pm 5.8$ \\
\hline$\dot{\mathrm{V}}_{2 \text { peak }}, \mathrm{mL} /(\mathrm{kg} \cdot \mathrm{min})$ & $34.5 \pm 7.2$ & $42.8 \pm 6.8 \dagger$ & $33.5 \pm 1.7$ & $32.9 \pm 6.6$ \\
\hline Maximum heart rate, beats/min & $181.8 \pm 8.9$ & $189.5 \pm 10.3 \dagger$ & $177.5 \pm 15.1$ & $172.7 \pm 8.1$ \\
\hline Power output, W & $313.3 \pm 52.1$ & $331.0 \pm 59.7$ & $256.7 \pm 36.1$ & $250.0 \pm 37.4$ \\
\hline \multicolumn{5}{|c|}{$\begin{array}{l}\text { IQR }=\text { interquartile range; } \mathrm{SD}=\text { standard deviation; } \dot{\mathrm{V}}_{2 \text { 2paek }}=\text { maximal volume of oxygen consumption. } \\
{ }^{*} \text { Except where noted otherwise. } \\
\text { tSignificantly different from male surgical residents at } p<0.05\end{array}$} \\
\hline
\end{tabular}

smaller samples. Therefore, the observed differences between surgical and nonsurgical residents appear, in this sample, to be solely due to the differences between the male surgical and male nonsurgical residents.

Nonsurgical residents of both sexes and female surgical residents had BMI values that are considered healthy by Health Canada, ${ }^{24}$ but the male surgical residents would be considered overweight. However, all participants would be considered healthy in terms of body fat percentage. ${ }^{20}$

It is interesting to note that, although there were observed differences in physical fitness between surgical and nonsurgical residents, there was no difference in self-reported physical activity time per week. This may be due to the surgical residents' overestimating the time they spent exercising or performing physical activity in a fatigued state after long work hours, which would have prevented them from obtaining optimal relative health gains. ${ }^{25}$

It is well described that physical fitness is associated with positive health outcomes such as improved cardiovascular health, ${ }^{26}$ improved mental health, ${ }^{27}$ reduction in allcause mortality risk ${ }^{28}$ and improved work performance. ${ }^{29}$ Although the male surgical residents in our study portrayed the greatest risk factors for decreased physical health, it is important that all medical residents maintain a healthy lifestyle through self-care, nutrition and exercise to benefit their long-term physical, mental and emotional health. High BMI and low $\dot{V}_{o_{\text {2peak }}}$ scores have been associated with increased risk of cardiovascular disease, ${ }^{30-32}$ cancer, ${ }^{31,32}$ diabetes ${ }^{31,33}$ hypertension, hypercholesterolemia and metabolic syndrome, ${ }^{34}$ whereas, overall, exercise has been found to be beneficial as a therapy for 26 chronic diseases. ${ }^{35}$ Specifically, an improvement in $\dot{V}_{\mathbf{O}_{2 \text { peak }}}$ of $3.5 \mathrm{~mL} /(\mathrm{kg} \cdot \mathrm{min})$ has been found to lower the risk of all- cause mortality by $15 \%$ and the risk of mortality due to cardiovascular disease by $19 \% .{ }^{36}$ Medical faculties and especially surgical program directors should therefore implement strategies to encourage self-care and promote physical health.

Overall resident health is important professionally since physicians must promote a healthy lifestyle to their patients. Physicians who exercise regularly (both aerobic and strength-training-type exercise) are more likely to counsel patients on the benefits of such activities and to report better compliance by patients. ${ }^{37}$ These physicians tend to be younger, with a newer practice. ${ }^{37}$ Furthermore, physicians' success in motivating patients to maintain a healthy lifestyle is enhanced if they themselves are not obese $^{38}$ and if they model healthy habits. ${ }^{39}$

\section{Limitations}

Limitations to this study include a potential selection bias. Residents who perceived themselves as physically fit may have been more likely to participate. However, we believe that this bias would have been present in both groups. Also, the small sample of female participants did not allow for any definitive conclusions to be drawn. Furthermore, the residents' nutritional status and the specific type of physical activity they engaged in were not included in this study, both of which may have influenced the observed results.

\section{Conclusion}

Surgical residents had poorer aerobic fitness levels and higher BMI than nonsurgical residents. Male surgical residents fall in the 20th percentile for recommended aerobic 
fitness. ${ }^{18}$ Longer work hours may contribute to the lower aerobic fitness and increased BMI and body fat of surgical residents. To decrease the health-related risks associated with these physical and physiologic markers, a wellbalanced diet and increased exercise is recommended.

Acknowledgment: The authors acknowledge the Pan Am Clinic Foundation for its support.

Affiliations: From the Department of Surgery, University of Manitoba, Winnipeg, Man. (Perrin, Leiter, MacDonald) and the Pan Am Clinic Foundation, Winnipeg, Man. (Cordingley, Leiter, MacDonald).

Funding: Funding for the research was provided by the Pan Am Clinic Foundation.

Competing interests: None declared.

Contributors: All authors designed the study. D. Perrin, D. Cordingley and J. Leiter acquired and analyzed the data and wrote the article. All authors reviewed the article and approved the final version for publication.

\section{References}

1. Mettner J. Walking the talk. Minn Med 2012;95:11-2.

2. Daneshvar F, Weinreich M, Daneshvar D, et al. Cardiorespiratory fitness in internal medicine residents: Are future physicians becoming deconditioned? 7 Grad Med Educ 2017;9:97-101.

3. Cohen JS, Patten S. Well-being in residency training: a survey examining resident physician satisfaction both within and outside of residency training and mental health in Alberta. BMC Med Educ 2005;5:21.

4. Fletcher KE, Reed DA, Arora VM. Patient safety, resident education and resident well-being following implementation of the 2003 ACGME duty hour rules. 7 Gen Intern Med 2011;26:907-19.

5. Peets A, Ayas NT. Restricting resident work hours: the good, the bad, and the ugly. Crit Care Med 2012;40:960-6.

6. Immerman I, Kubiak EN, Zuckerman JD. Resident work-hour rules: a survey of residents' and program directors' opinions and attitudes. Am 7 Orthop (Belle Mead N7) 2007;36:E172-9, discussion E179.

7. Henning MA, Hawken SJ, Hill AG. The quality of life of New Zealand doctors and medical students: What can be done to avoid burnout? N Z Med F 2009;122:102-10.

8. Czeisler CA. Medical and genetic differences in the adverse impact of sleep loss on performance: ethical considerations for the medical profession. Trans Am Clin Climatol Assoc 2009;120:249-85.

9. Papp KK, Miller CM, Strohl KP. Graduate medical training, learning, relationships, and sleep loss. Sleep Med Rev 2006;10:339-45.

10. Mountain SA, Quon BS, Dodek P, et al. The impact of housestaff fatigue on occupational and patient safety. Lung 2007;185:203-9.

11. Suskin N, Ryan G, Fardy J, et al. Clinical workload decreases the level of aerobic fitness in housestaff physicians. 7 Cardiopulm Rebabil 1998;18:216-20.

12. Arora R, Lettieri C, Claybaugh JR. The effects of residency on physical fitness among military physicians. Mil Med 2004;169:522-5.

13. De Pauw K, Roelands B, Cheung SS, et al. Guidelines to classify subject groups in sport-science research. Int 7 Sports Physiol Perform 2013;8:111-22.

14. Yuhasz MS. Physical fitness manual. London (ON): University of Western Ontario; 1974.

15. The Canadian physical activity, fitness and lifestyle approach: CSEP-Health of Fitness Program's health-related appraisal and counselling strategy. 3rd ed. Ottawa: Canadian Society for Exercise Physiology; 2003.

16. Gledhill N, Jamnik V. Detailed assessment protocols for NHL entry draft players. Toronto: York University; 2007.
17. Howley ET, Bassett DR Jr, Welch HG. Criteria for maximal oxygen uptake: review and commentary. Med Sci Sports Exerc 1995;27:1292301.

18. American College of Sports Medicine. ACSM's guidelines for exercise testing and prescription. 9th ed. Riverwoods (IL): Wolters Kluwer Health/Lippincott Williams \& Wilkins; 2013.

19. Kuczmarski MF, Kuczmarski RJ, Najjar M. Effects of age on validity of self-reported height, weight, and body mass index: findings from the third National Health and Nutrition Examination Survey, 19881994. F Am Diet Assoc 2001;101:28-34.

20. Lohman TG, Houtkooper L, Going SB. Body fat measurement goes high-tech: not all are created equal. ACSMs Health Fit 7 1997; $1: 30-5$.

21. Reckelhoff JF. Gender differences in the regulation of blood pressure. Hypertension 2001;37:1199-208.

22. Silverman IW. The secular trend for grip strength in Canada and the United States. 7 Sports Sci 2011;29:599-606.

23. Stefani RT. The relative power output and relative lean body mass of World and Olympic male and female champions with implications for gender equity. 7 Sports Sci 2006;24:1329-39.

24. Canadian guidelines for body weight classification in adults. Ottawa: Health Canada; 2003.

25. Eijsvogels TMH, George KP, Thompson PD. Cardiovascular benefits and risks across the physical activity continuum. Curr Opin Cardiol 2016;31:566-71.

26. Wessel TR, Arant CB, Olson MB, et al. Relationship of physical fitness vs body mass index with coronary artery disease and cardiovascular events in women. FAMA 2004;292:1179-87.

27. Jeoung BJ, Hong MS, Lee YC. The relationship between mental health and health-related physical fitness of university students. $\mathcal{F}$ Exerc Rebabil 2013;9:544-8.

28. Sandvik L, Erikssen J, Thaulow E, et al. Physical fitness as a predictor of mortality among healthy, middle-aged Norwegian men. $N$ Engl 7 Med 1993;328:533-7.

29. Pronk NP, Martinson B, Kessler RC, et al. The association between work performance and physical activity, cardiorespiratory fitness, and obesity. 7 Occup 2004;46:19-25.

30. Jousilahti P, Tuomilehto J, Vartiainen E, et al. Body weight, cardiovascular risk factors, and coronary mortality: 15-year follow-up of middle-aged men and women in eastern Finland. Circulation 1996;93:1372-9.

31. Baik I, Ascherio A, Rimm EB, et al. Adiposity and mortality in men. Am 7 Epidemiol 2000;152:264-71.

32. Evans MF, Frank J. Body weight and mortality among women. Can Fam Physician 1997;43:455.

33. Ford ES, Williamson DF, Liu S. Weight change and diabetes incidence: findings from a national cohort of US adults. Am 7 Epidemiol 1997;146:214-22.

34. Janssen I, Katzmarzyk PT, Ross R. Body mass index, waist circumference, and health risk: evidence in support of current National Institutes of Health guidelines. Arch Intern Med 2002;162:2074-9.

35. Pedersen BK, Saltin B. Exercise as medicine - evidence for prescribing exercise as therapy in 26 different chronic diseases. Scand $\mathcal{F}$ Med Sci Sports 2015;25(Suppl 3):1-72.

36. Lee DC, Sui X, Artero EG, et al. Long-term effects of changes in cardiorespiratory fitness and body mass index on all-cause and cardiovascular disease mortality in men: the Aerobics Center Longitudinal Study. Circulation 2011;124:2483-90.

37. Abramson S, Stein J, Schaufele M, et al. Personal exercise habits and counseling practices of primary care physicians: a national survey. Clin 7 Sport Med 2000;10:40-8.

38. Hash RB, Munna RK, Vogel RL, et al. Does physician weight affect perception of health advice? Prev Med 2003;36:41-4.

39. Frank E, Breyan J, Elon L. Physician disclosure of healthy personal behaviors improves credibility and ability to motivate. Arch Fam Med 2000;9:287. 